\title{
A unique eukaryotic $\beta$-xylosidase gene from the phytopathogenic fungus Cochliobolus carbonum
}

\author{
Sigrun Wegener, Richard F. Ransom† and Jonathan D. Walton \\ Author for correspondence: Jonathan D. Walton. Tel: +1 517353 4885. Fax: + 15173539168. \\ e-mail: walton@pilot.msu.edu
}

Department of Energy Plant Research Laboratory, Michigan State University, East Lansing, MI 48824, USA

\begin{abstract}
The plant-pathogenic fungus Cochliobolus carbonum secretes one major $\beta$ xylosidase (Xyp1) when grown on xylan or maize cell walls. CDNA and genomic DNA encoding Xyp1 were isolated using PCR primers based on peptide sequences from the purified protein. XYP1 contains three introns, has 5' and 3' untranslated regions of 74 and 145 bp, respectively, and is predicted to encode a protein of 328 amino acids $\left(M_{r} 36700\right)$ with four $\boldsymbol{N}$-glycosylation sites. Although it is secreted, Xyp1 has no predicted signal peptide. Furthermore, Xyp1 appears not to be processed at the $\mathrm{N}$-terminus because one of the peptides isolated from the mature protein is located only six amino acids downstream of the translational start methionine. The primary sequence of Xyp 1 is unrelated to any known eukaryotic $\beta$-xylosidase but has $35 \%$ overall identity to two bacterial bifunctional $\beta$-xylosidase $/ \alpha$-arabinosidases. Mutation of XYP1 by targeted gene replacement resulted in the loss of the major $\beta$ xylosidase activity corresponding to the product of XYP1, but a significant amount of secreted $\beta$-xylosidase activity ( $25 \%$ of wild-type) remained in the culture filtrates. The xyp1 mutant was still fully pathogenic on maize.
\end{abstract}

Keywords: Cochliobolus (Helminthosporium) carbonum, $\beta$-xylosidase, xylanase, plant pathogen, cell-wall-degrading enzyme

\section{INTRODUCTION}

A major long-standing question in plant pathology is the role of cell-wall-degrading enzymes in the process of pathogenesis. Plant-pathogenic bacteria and fungi make xylan-degrading enzymes, but evidence with regard to the role of most of these enzymes in ingress, ramification or the acquisition of nutrients is inconclusive. The major obstacle to answering this question is enzymic redundancy: most micro-organisms, including plant pathogens, make multiple xylan-degrading enzymes (Apel-Birkhold \& Walton, 1996).

A variety of enzymes that can degrade xylans have been identified, and their genes cloned, from saprophytic prokaryotes and eukaryotes (Wong et al., 1988). Many, perhaps most, microbial plant pathogens make xylan-

\footnotetext{
†Present address: Department of Pediatric Nephrology, University of Michigan Medical Center, Ann Arbor, MI 48109, USA.

The GenBank accession number for the nucleotide sequence reported in this paper is AF095243.
}

degrading enzymes (Maino et al., 1974; Anderson, 1988; Dean et al., 1989; Southerton et al., 1993; Wu et al., 1997). The role of xylan-degrading enzymes has been studied genetically in two plant-pathogenic fungi. Cochliobolus carbonum, which causes Northern corn leaf spot, attacks foliage, stems and ears of susceptible maize varieties. It makes at least two endo-1,4- $\beta$ xylanases as well as $\beta$-xylopyranosidase in culture (Apel et al., 1993; Apel-Birkhold \& Walton, 1996; Ransom \& Walton, 1997). A strain of C. carbonum mutated in three of its four Family G endoxylanase genes (XYL1, $X Y L 2$ and $X Y L 3$ ) was fully pathogenic and grew at the wild-type rate on xylan or maize cell walls (ApelBirkhold \& Walton, 1996). Magnaporthe grisea, cause of blast of rice, makes at least six endoxylanases in culture and two xylanase genes, XYL1 and XYL2, have been cloned (Wu et al., 1995, 1997). Strains of M. grisea mutated in XYL1 (Family G) and XYL2 (Family F) have reduced ability to grow on xylan as carbon source but are still fully pathogenic (Wu et al., 1997).

The complete degradation of xylan requires the participation not only of endoxylanases but also $\beta$ - 
xylosidase (Xyp) (Wong et al., 1988). Therefore, a full evaluation of the role of xylan degradation in the process of plant pathogenesis requires a genetic analysis of genes encoding Xyp as well as endoxylanases. C. carbonum makes one major extracellular Xyp, called Xyp1, when grown in culture on maize cell walls as a carbon source (Ransom \& Walton, 1997). Xyp1 is glycosylated, has a low level of $\alpha$-arabinosidase activity but no arabinanase activity, a $\mathrm{pH}$ optimum of $5 \cdot 5-6 \cdot 5$, and a temperature optimum of $37^{\circ} \mathrm{C}$. Xyp1 prefers xylobiose as substrate but can also release reducing sugars from several complex plant xylans, including oat spelts xylan, birch wood xylan and wheat arabinoxylan. Xylose is the sole sugar released by Xyp1 from oat spelts xylan (Ransom \& Walton, 1997).

Genes encoding Xyp have been isolated from saprophytic bacteria and fungi and from at least one prokaryotic plant pathogen (Vroemen et al., 1995), but to the best of our knowledge this is the first report of a Xyp gene, XYP1, from a plant-pathogenic fungus. The predicted protein sequence of XYP1 has some similarity to two prokaryotic Xyp proteins but not to any known fungal Xyp.

\section{METHODS}

Fungal strains and growth. Methods used for storage and growth of C. carbonum and preparation of maize cell wall growth medium have been described previously (Sposato $e t$ al., 1995).

Nucleic acid manipulations. DNA and RNA were isolated as described by Pitkin et al. (1996). The methods used for DNA blotting, probe labelling, hybridization and genomic and cDNA library screening have been described previously (ScottCraig et al., 1990; Murphy \& Walton, 1996).

The XYP1 gene was isolated using PCR primers corresponding to the Xyp1 amino acid sequences DIPWAT and DKPLGK (Ransom \& Walton, 1997). The PCR primers had the sequences 5'-GAYATHCCNTGGGCNAC (96-fold degenerate) and 5'-TTNCCNARNGGYTTRTC (512-fold degenerate) ( $Y$ represents $\mathrm{C}$ or $\mathrm{T} ; \mathrm{H}$ represents $\mathrm{A}, \mathrm{T}$ or $\mathrm{C} ; \mathrm{R}$ represents $\mathrm{A}$ or $\mathrm{G}$; and $\mathrm{N}$ represents any nucleotide). Genomic DNA was used as template in PCR carried out in a Perkin-Elmer thermocycler under the following conditions: $3 \mathrm{~min}$ denaturation at $94^{\circ} \mathrm{C} ; 35$ cycles of 1 min denaturation at $94^{\circ} \mathrm{C}, 2 \mathrm{~min}$ annealing at $55^{\circ} \mathrm{C}$, and $3 \mathrm{~min}$ primer extension at $72{ }^{\circ} \mathrm{C}$. The final step was $10 \mathrm{~min}$ primer extension at $72{ }^{\circ} \mathrm{C}$. A $141 \mathrm{bp}$ fragment was amplified, cloned, sequenced, and used to screen cDNA and genomic libraries. A $5 \cdot 0 \mathrm{~kb}$ Sal genomic fragment that hybridized to an isolated $1 \cdot 2 \mathrm{~kb}$ cDNA was subcloned into pBluescript II SK(-). The cDNA and the genomic DNA spanning the gene were sequenced on both strands. Sequencing was performed by automated fluorescent sequencing at the MSU-DOE-PRL Plant Biochemistry facility using an Applied Biosystems Catalyst 800 for Taq cycle sequencing and an Applied Biosystems 373A Sequencer for analysis of the products.

The transcription start site of XYP1 was determined using a $5^{\prime}$ RACE (Rapid Amplification of cDNA Ends) kit (Gibco) (Frohman et al., 1988). Reverse transcription was primed with the oligonucleotide 5'-GGCTGGGAAGAACAGGTA (the reverse complement of 5'-TACCTGTTCTTCCCAGCC

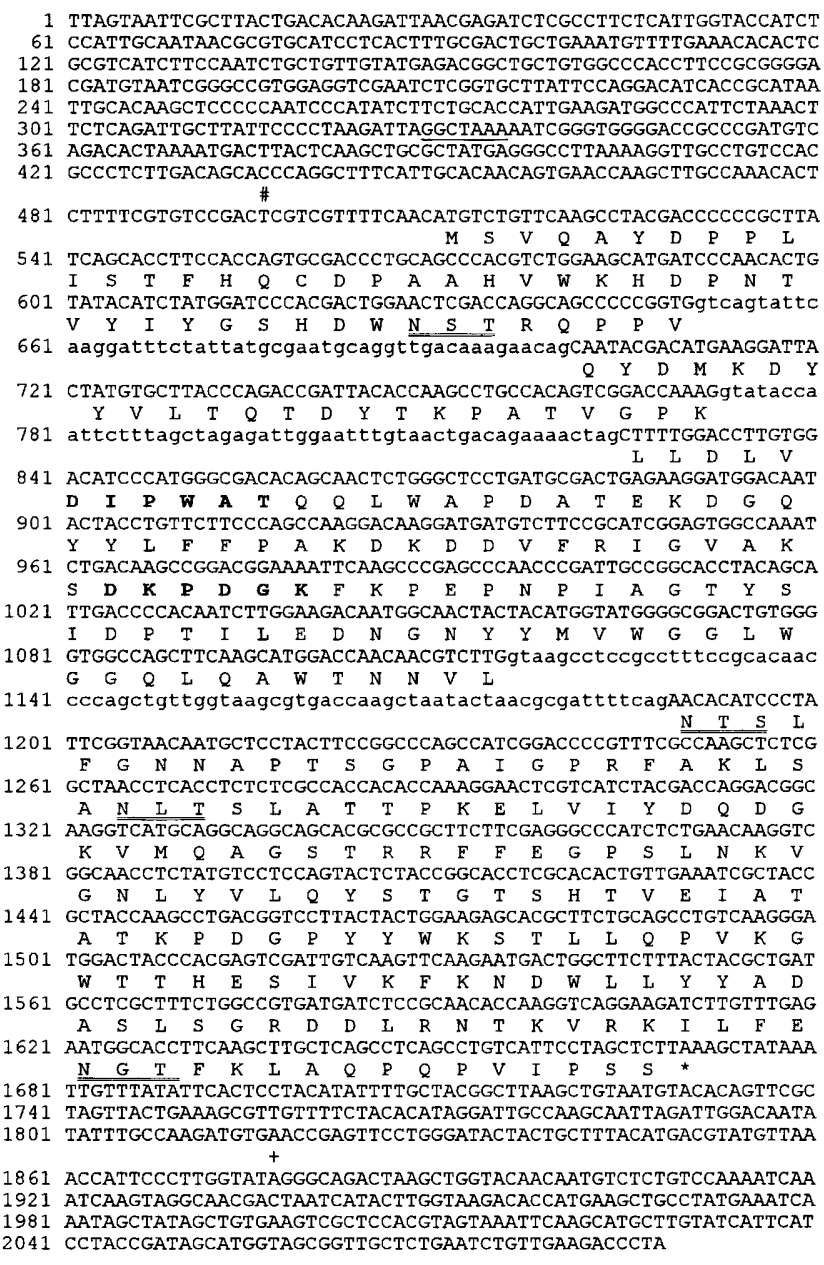

Fig. 1. DNA and deduced amino acid sequences of XYP1. Amino acids are shown below the corresponding codons. The two peptides used for the design of PCR primers are printed in bold type. The sequence in the promoter that is identical to the $x \ln R$-binding site is underlined. The three introns are indicated by lower-case letters. The four potential glycosylation sites are doubly underlined. \#, Transcriptional start site; *, stop codon; + , polyadenylation site (all symbols refer to the nucleotide directly above).

starting at nucleotide 903; see Fig. 1). PCR amplification was done using the primer sequence 5'-CCAGTCGTGGGATCCATAGAT (the reverse complement of 5'-ATCTATGGATCCCACGACTGG starting at nucleotide 606; see Fig. 1) and the 'abridged anchor' primer supplied with the RACE kit. Three independent RACE products were sequenced. Two products started at nucleotide 436 , and one product started at nucleotide 448 (see Fig. 1).

Transformation-mediated gene replacement. The central part of the coding region of XYP1 was excised from the $5.0 \mathrm{~kb}$ genomic SalI fragment by cutting with $B g l I I$, and replaced with the Escherichia coli $h p h$ gene (encoding hygromycin phosphotransferase) driven by the Aspergillus nidulans trpC promoter from plasmid pCB1003 (Carroll et al., 1994). In this way, the complete coding region of XYP1 except for $60 \mathrm{bp}$ of the $3^{\prime}$ end was removed. The fragment used for transformation was released from the vector by cutting with SalI. Protoplast isolation and transformation have been described previously 
(Scott-Craig et al., 1990; Apel et al., 1993). The transformants were subjected to two rounds of single-spore isolation to ensure nuclear homogeneity.

Protein purification and enzyme assays. C. carbonum wildtype and mutant strains were grown in 11 flasks containing $125 \mathrm{ml}$ modified Fries' medium (Van Hoof et al., 1991) containing sucrose at $0 \cdot 2 \%$ and maize cell walls at $1 \%(\mathrm{w} / \mathrm{v})$. Xyp1 was purified as described by Ransom \& Walton (1997). $\beta$-Xylosidase activity was determined using $p$-nitrophenyl $\beta$-Dxylopyranoside (Sigma N2132) (Ransom \& Walton, 1997).

\section{RESULTS AND DISCUSSION}

\section{Isolation and characterization of XYP1}

A 141 bp PCR product was obtained using PCR primers based on two internal peptides from purified Xyp1 (Ransom \& Walton, 1997). The PCR product was used to screen cDNA and genomic DNA libraries and both cDNA and genomic copies of the encoding gene, XYP1, were sequenced (Fig. 1). The predicted amino acid sequence of XYP1 contains the two peptides previously reported from purified Xyp1 (Ransom \& Walton, 1997). Peptide 1 (LLDLVDIPWATQQLWA) is a perfect match, but peptide 2 contains three discrepancies, including one in the sequence upon which one of the PCR primers was designed. The predicted sequence of XYP1 also contains three additional peptides derived from the purified protein by trypsin or Asp-N digestion, namely FFEGPSLNK, TKPATVGP and LLDLVDIP. The third of these peptides overlaps with peptide 1.

$X Y P 1$ contains three introns of 51,52 and $73 \mathrm{bp} . X Y P 1$ has a $5^{\prime}$ untranslated region of $74 \mathrm{bp}$ and a $3^{\prime}$ untranslated region of $145 \mathrm{bp}$. In the promoter there is a sequence (GGCTAAA; underlined in Fig. 1) identical to the binding site for the product of $x \ln R$, a zinc binuclear $\mathrm{Cys}_{6}$ transcription factor that regulates endo-1,4- $\beta$ xylanase and $\beta$-xylosidase gene expression in Aspergillus niger (van Peij et al., 1998).

XYP1 is predicted to encode a protein of 328 amino acids with an $M_{\mathrm{r}}$ of 36700 , which is slightly smaller than the $M_{\mathrm{r}}(42000)$ estimated by SDS-PAGE (Ransom \& Walton, 1997). Xyp1 is a glycoprotein (Ransom \& Walton, 1997), and the amino acid sequence has four potential $\mathrm{N}$-glycosylation sites (Fig. 1). Therefore, the difference between the calculated and the experimentally determined sizes is probably due to post-translational glycosylation.

\section{Xyp1 contains no apparent signal peptide}

All of the 14 known extracellular cell-wall-degrading enzymes of C. carbonum (Görlach et al., 1998; ScottCraig et al., 1998) contain canonical eukaryotic signal peptide sequences according to the SignalP program (Nielsen et al., 1997), which is based on the rules of von Heijne (1986). Calculated signal peptide lengths for the C. carbonum enzymes range from 15 to 19 amino acids with a mean of 18 . The most highly conserved positions are Ala at -2 (12 of 14) and Pro at +2 (12 of 14).
In contrast to all other known C. carbonum extracellular enzymes, however, the SignalP program did not predict any cleavage site for Xyp 1 within the first 50 amino acids. In addition, the first 20 amino acids of Xyp1 are not rich in hydrophobic residues: whereas $41 \%$ of the amino acids of the known C. carbonum signal peptides are Ala or Leu, only $15 \%$ of the first 20 amino acids of Xyp1 are. There are no other Met codons or any predicted signal peptide in any reading frame between the experimentally determined transcriptional start and the proposed Met start codon (Fig. 1). The length of the $5^{\prime}$ untranscribed region is consistent with other C. carbonum genes, and the context of the predicted Met start codon agrees with the consensus for filamentous fungi (CAACATGTC vs the consensus CAMMATGNC, where $\mathrm{M}$ is $\mathrm{A}$ or $\mathrm{C}$, and $\mathrm{N}$ is any nucleotide) (Edelmann \& Staben, 1994). Therefore, the apparent lack of a signal peptide is probably not due to misidentification of the putative translational start site.

Additional evidence against Xyp1 being processed during secretion is that another peptide sequence obtained experimentally from Xyp 1 by Asp- $\mathrm{N}$ digestion had the sequence DPKLISTFHQKA. Starting at amino acid 7 (Fig. 1) is the predicted sequence DPpLISTFHQcd, which agrees in nine of twelve positions (discrepancies are indicated in lower case). Assuming that the discrepancies are due to errors in the peptide sequencing, the presence of this peptide in mature Xyp1 indicates that, if Xyp1 is at all processed post-translationally, it loses no more than six amino acids.

Other proteins have been described that are secreted but lack a cleaved hydrophobic signal peptide (Muesch et al., 1990). Chicken ovalbumin and human plasminogen activator inhibitor- 2 contain uncleaved internal signal sequences that are located near their $\mathrm{N}$-termini, which allow these proteins to be secreted by the normal secretory pathway through the endoplasmic reticulum (ER) and the Golgi apparatus (Meek et al., 1982; Ye et al., 1988). The fact that Xyp1 is glycosylated and contains four potential $\mathrm{N}$-glycosylation sites speaks for a secretion mechanism through the classical ER/Golgi pathway. However, it is not known if Xyp1 is truly $\mathrm{N}$ glycosylated as opposed to O-glycosylated. In contrast to ovalbumin, Xyp1 does not contain a stretch of hydrophobic residues near its $\mathrm{N}$-terminus or anywhere else in the protein that could plausibly function as an uncleaved internal signal peptide. On the other hand, several other proteins that lack a secretory signal sequence are instead secreted by pathways other than the ER/Golgi pathway. These proteins include annexins (Siever \& Erickson, 1997), mammalian basic fibroblast growth factor (Mignatti et al., 1992), interleukin-1 $\beta$ (Rubartelli et al., 1990) and the mating a-factor of Saccharomyces cerevisiae (Kuchler et al., 1989). The secretion of a-factor is dependent on STE6, which encodes a plasma membrane P-glycoprotein. $S$. cerevisiae also has protein secretory pathways that are independent of either the classical secretory pathway or STE6 (Cleves et al., 1996). Thus, the lack of a signal peptide in Xyp1 is unusual but not unprecedented. It 


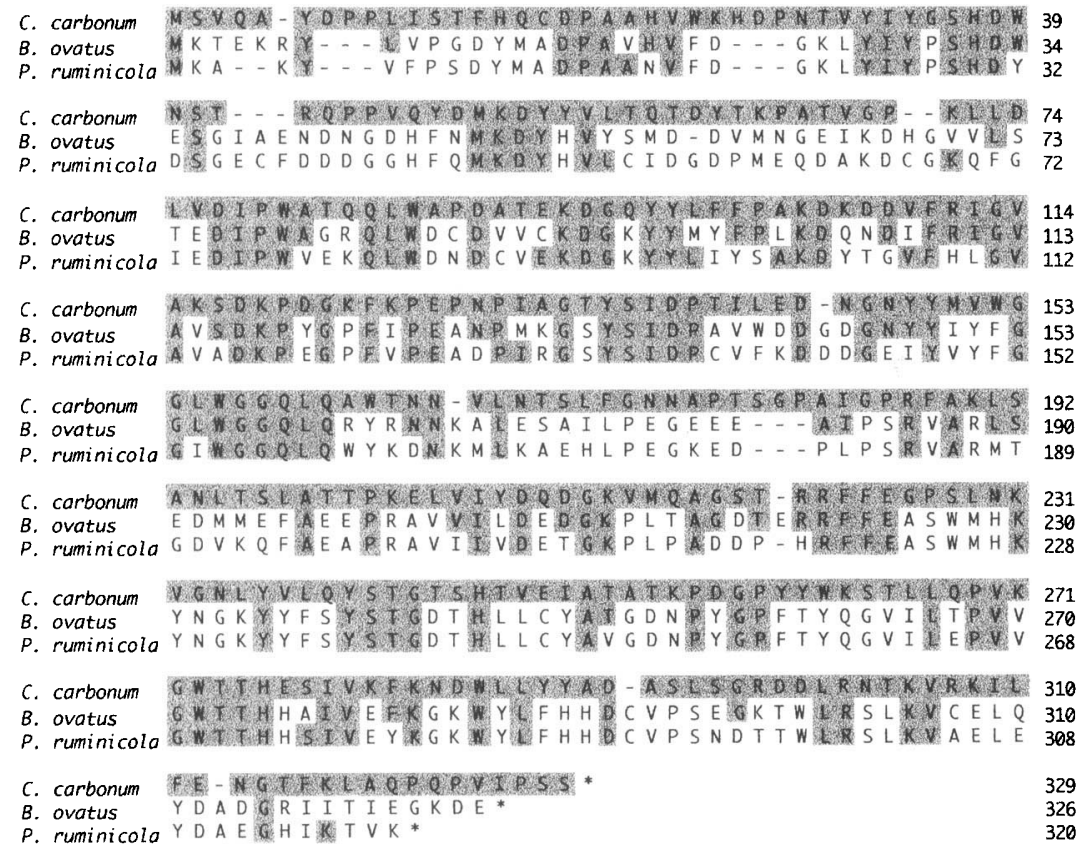

Fig. 2. Comparison of the deduced amino acid sequence of Xyp1 to two related bacterial $\beta$-xylosidase sequences. Sequence references: Bacteroides ovatus, GenBank accession no. U04957, Whitehead (1995); Prevotella ruminicola, GenBank accession no. Z49241, Gasparic et al. (1995). Amino acids in the other two enzymes that are identical to Xyp1 are shaded. Dashes indicate introduced sequence gaps; asterisks indicate stop codons. would be interesting to determine if alternative protein export mechanisms exist in filamentous fungi.

\section{Xyp1 is related to bacterial but not fungal xylosidases}

By BLAST analysis (Altschul et al., 1990), Xyp1 is not related to any of the six fungal $\beta$-xylosidases in the current database. Xyp1 is related in both size and primary sequence to two bacterial $\beta$-xylosidases, those of Bacteroides ovatus ( $35 \%$ overall identity) and Prevotella (formerly Bacteroides) ruminicola $(30 \%$ identity) (Whitehead \& Hespell, 1990; Whitehead, 1995; Gasparic et al., 1995) (Fig. 2). Interestingly, neither of these two bacterial xylosidases has an obvious signal peptide. On this basis, the $\beta$-xylosidase of $P$. ruminicola was presumed to be located in the cytoplasm, although this has apparently not been experimentally tested (Gasparic et al., 1995).

Both of the related bacterial $\beta$-xylosidases have been assigned to Family 43 of glycosylhydrolases (Henrissat $\&$ Bairoch, 1996). The B. ovatus enzyme is a bifunctional $\beta$-xylosidase $/ \alpha$-arabinosidase, and the $P$. ruminicola enzyme has in addition exoxylanase activity, defined as the ability to release free xylose from xylan. Xyp1 resembles the $P$. ruminicola enzyme in having exoxylanase activity, but it cannot be considered to be bifunctional because its $\alpha$-arabinosidase activity is only $12 \%$ of its $\beta$-xylosidase activity (Ransom \& Walton, 1997). The sole fungal enzyme currently placed in Family 43 is an endoarabinanase from $A$. niger, but this enzyme and Xyp1 show no overall amino acid similarity, the largest region of identity being composed of five amino acids, LWAPD (Flipphi et al., 1993). Xyp1 is not active against sugar-beet arabinan (Ransom \& Walton, 1997). Xyp1 is therefore unusual in two respects. First, it is related to bacterial $\beta$-xylosidases but not to any other known fungal $\beta$-xylosidase. Secondly, although it is clearly secreted, the predicted protein lacks any typical signal peptide and, based on peptide sequences obtained from the mature protein, is probably not post-translationally cleaved.

\section{Gene replacement of XYP1}

To test that XYP1 encodes the enzymically characterized Xyp1 protein, and to analyse the role of Xyp1 in pathogenesis, we constructed a strain of C. carbonum in which XYP1 was disrupted by gene replacement (Fig. 3a). Two Tox $2^{+}$(HC-toxin-producing) strains of $C$. carbonum (367-1a and 367-2A) were transformed with a vector in which the majority of the XYP1 coding sequence had been replaced by a gene, $h p h$, conferring hygromycin resistance. A total of 36 hygromycinresistant transformants were obtained, and one transformant of each strain (T661-1 and T666-2) was further analysed. The restriction map of the wild-type XYP1 locus and the predicted map resulting from homologous integration of a single copy of the replacement vector are shown in Fig. 3(a). The patterns of hybridization with the BglII fragment of XYP1, the complete SalI genomic fragment of $X Y P 1$, or the $h p h$ gene indicate that the XYP1 gene had been deleted in both transformants (Fig. 3b).

Growth of the mutant T661-1 on maize cell walls, birchwood xylan or oat spelts xylan was not significantly different from wild-type (data not shown). Total extracellular $\beta$-xylosidase activity in culture filtrates of T6611 grown on maize cell walls was reduced by $75 \%$ compared to wild-type. $\beta$-Xylosidase activities from wild-type and T661-1 were purified in parallel through cation-exchange HPLC, as described by Ransom \& Walton (1997). The xyp1 mutant completely lacked the major peak of xylosidase activity, but contained a small 
(a)
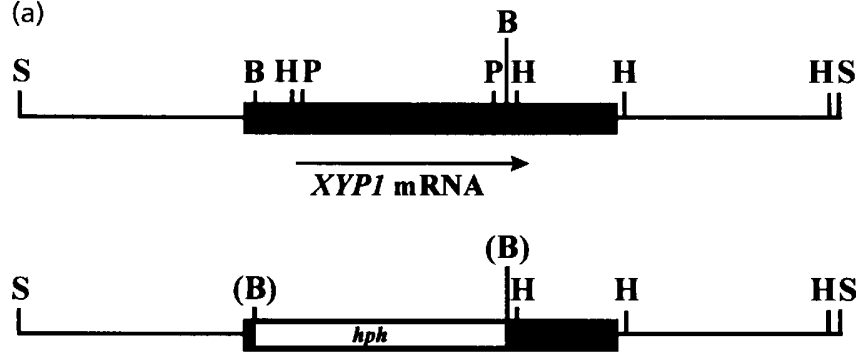

$0.5 \mathrm{~kb}$

(b)
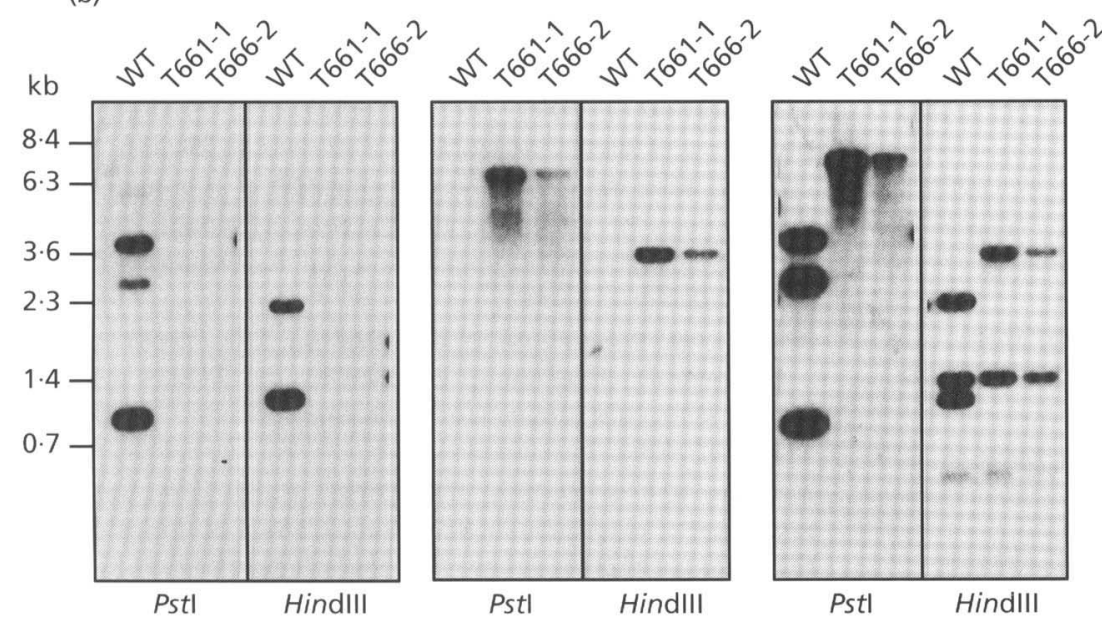

Fig. 3. DNA blot analysis of wild-type and XYP1 disruption mutants. (a) Genomic restriction maps of the wild-type XYP1 locus (top) and of the XYP1 locus after transformation with the replacement vector (bottom). The region that was sequenced (Fig. 1) is in black. The position and direction of transcription of the XYP1 ORF is shown by the arrow. S, Sall; B, Bg/II; H, HindIII; P, Pstl. (b) DNA blot comparing wild-type and two XYP1 replacement transformants (T6611 and T666-2). DNA was cut with Pstl or HindIII as indicated. The blots were probed with the XYP1 Bg/ll fragment (panels on left-hand side), a cDNA copy of $h p h$ (middle panels) or the complete XYP1 $5.0 \mathrm{~kb}$ Sall genomic fragment (panels on right-hand side). Fragment sizes are indicated on the left.

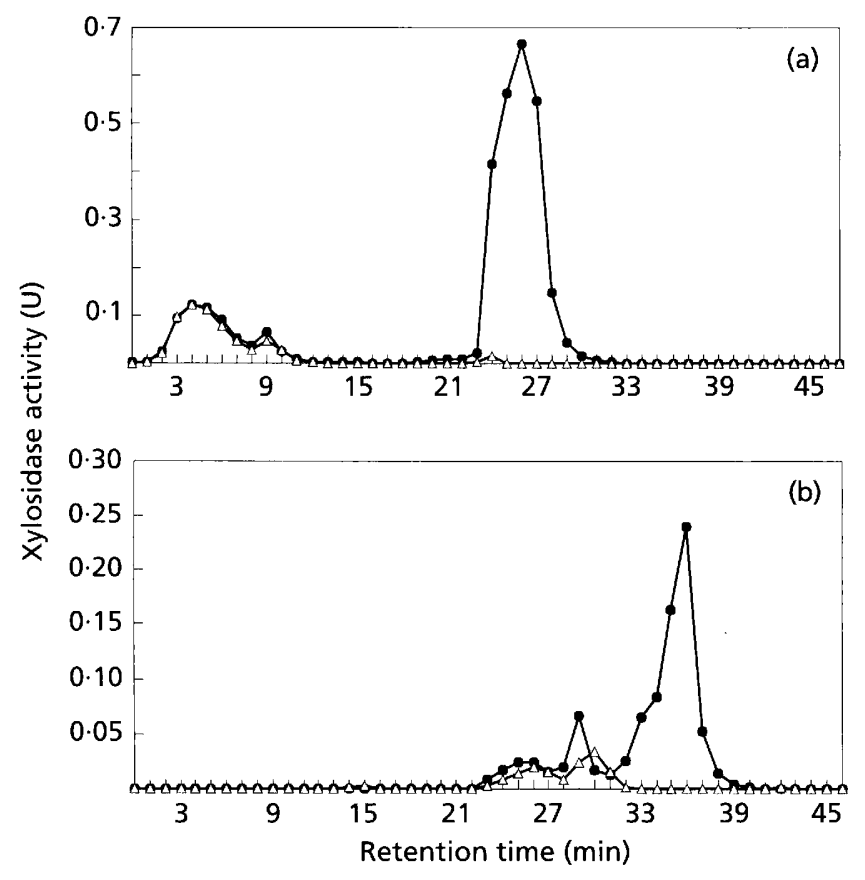

Fig. 4. Cation-exchange HPLC fractionation of culture filtrates from wild-type (367-1a) and the XYP1 mutant T661-1. Columns were run at $\mathrm{pH} 5.0$ (a) or $\mathrm{pH} 4.0$ (b). , 367-1a; $\triangle$, T661-1. One unit of xylosidase activity is defined as the amount producing $1 \mu \mathrm{g} p$-nitrophenol $\mathrm{min}^{-1} \mathrm{ml}^{-1}$. peak of $\beta$-xylosidase activity in the void fraction (Fig. $4 a)$. When the cation-exchange column was run at $\mathrm{pH} 4$ rather than $\mathrm{pH} 5$, the residual activity was retained on the column and was eluted as two small peaks, 7 and $10 \mathrm{~min}$ before the major activity attributable to Xyp1 (Fig. 4b). We conclude that C. carbonum must have at least one additional gene that encodes another extracellular enzyme with $\beta$-xylosidase activity.

\section{Pathogenicity of the xyp1 mutant}

We compared wild-type and mutant strains on susceptible maize cultivars (genotype $h m 1 / h m 1$ ) in the greenhouse. Lesion size, lesion morphology and rate of lesion development were examined daily for $10 \mathrm{~d}$. No difference in lesion morphology could be detected between the wild-type and two independent transformants tested. Thus we conclude that XYP1 is neither essential for pathogenicity nor a major virulence factor. Since $C$. carbonum has at least one additional gene encoding a $\beta$-xylosidase, it is not possible to conclude conclusively that $\beta$-xylosidase has no role in pathogenicity or virulence.

\section{ACKNOWLEDGEMENTS}

This research was supported by grants to J.D. W. from the US Department of Energy, Division of Energy Biosciences, the US 
Department of Agriculture Competitive Grants Program, and the Michigan State University Research Excellence Fund. S.W. was supported by a fellowship from the Deutsche Forschungsgemeinschaft.

\section{REFERENCES}

Altschul, S. F., Gish, W., Miller, W., Myers, E. W. \& Lipman, D. J. (1990). Basic local alignment search tool. J Mol Biol 215, 403-410.

Anderson, A. J. (1988). Extracellular enzymes produced by Colletotrichum lindemuthianum and Helminthosporium maydis during growth on isolated bean and corn cell walls. Phytopathology 68, 1585-1589.

Apel, P. C., Panaccione, D. G., Holden, F. R. \& Walton, J. D. (1993). Cloning and targeted gene disruption of XYL1, a $\beta 1,4$-xylanase gene from the maize pathogen Cochliobolus carbonum. Mol Plant-Microbe Interact 6, 467-473.

Apel-Birkhold, P. C. \& Walton, J. D. (1996). Cloning, disruption, and expression of two endo- $\beta 1,4$-xylanase genes, XYL2 and $X Y L 3$, from Cochliobolus carbonum. Appl Environ Microbiol 62, 4129-4135.

Carroll, A. M., Sweigard, J. A. \& Valent, B. (1994). Improved vectors for selecting resistance to hygromycin. Fungal Genet Newsl 41, 22.

Cleves, A. E., Cooper, D. N. W., Barondes, S. H. \& Kelly, R. B. (1996). A new pathway for protein export in Saccharomyces cerevisiae. J Cell Biol 133, 1017-1026.

Dean, J. F. D., Gamble, H. R. \& Anderson, J. D. (1989). The ethylene biosynthesis-inducing xylanase: its induction in Trichoderma viride and certain plant pathogens. Phytopathology 79, 1071-1078.

Edelmann, S. E. \& Staben, C. (1994). A statistical analysis of sequence features within genes from Neurospora crassa. Exp Mycol 18, 70-81.

Flipphi, M. J. A., Panneman, H., Van der Veen, P., Visser, J. \& Degraaff, L. H. (1993). Molecular cloning, expression, and structure of the endo-1,5- $\alpha$-L-arabinase gene of Aspergillus niger. Appl Microbiol Biotechnol 40, 318-326.

Frohman, M. A., Dush, M. K. \& Martin, G. R. (1988). Rapid production of full-length cDNAs from rare transcripts: amplification using a single gene-specific oligonucleotide primer. Proc Natl Acad Sci USA 85, 8998-9002.

Gasparic, A., Martin, J., Daniel, A. S. \& Flint, H. J. (1995). A xylan hydrolase gene cluster in Prevotella ruminicola $\mathrm{B}_{1} 4$ : sequence relationships, synergistic interactions, and oxygen sensitivity of a novel enzyme with exoxylanase and $\beta-(1,4)$-xylosidase activities. Appl Environ Microbiol 61, 2958-2964.

Görlach, J. M., Van der Knaap, E. \& Walton, J. D. (1998). Cloning and targeted disruption of $M L G 1$, a gene encoding two of three extracellular mixed-linked glucanases in Cochliobolus carbonum. Appl Environ Microbiol 64, 385-391.

von Heijne, G. (1986). A new method for predicting signal sequence cleavage sites. Nucleic Acids Res 14, 4683-4690.

Henrissat, B. \& Bairoch, A. (1996). Updating the sequence-based classification of glycosyl hydrolases. Biochem J 316, 695-696.

Kuchler, K., Sterne, R. E. \& Thorner, J. (1989). Saccharomyces cerevisiae STE6 gene product : a novel pathway for protein export in eukaryotic cells. EMBO J 8, 3973-3984.

Maino, A. L., Schroth, M. N. \& Palleroni, N. J. (1974). Degradation of xylan by bacterial plant pathogens. Phytopathology 64, 881-885.

Meek, R. L., Walsh, K. A. \& Palmiter, R. D. (1982). The signal sequence of ovalbumin is located near the $\mathrm{NH}_{2}$ terminus. $J$ Biol Chem 257, 12245-12251.

Mignatti, P., Morimoto, T. \& Rifkin, D. B. (1992). Basic fibroblast growth factor, a protein devoid of secretory signal sequences, is released by cells via a pathway independent of the endoplasmic reticulum-Golgi complex. J Cell Physiol 151, 81-93.

Muesch, A., Hartmann, E., Rohde, K., Rubartelli, A., Sitia, R. \& Rapoport, T. A. (1990). A novel pathway for secretory proteins? Trends Biochem Sci 15, 86-88.

Murphy, J. M. \& Walton, J.D. (1996). Three extracellular proteases from Cochliobolus carbonum: cloning and targeted disruption of ALP1. Mol Plant-Microbe Interact 9, 290-297.

Nielsen, H., Engelbrecht, J., Brunak, S. \& von Heijne, G. (1997). Identification of prokaryotic and eukaryotic signal peptides and prediction of their cleavage sites. Protein Eng 10, 1-6.

van Peij, N. N. M. E., Visser, J. \& de Graaf, L. H. (1998). Isolation and analysis of $x \ln R$, encoding a transcriptional activator coordinating xylanolytic expression in Aspergillus niger. Mol Microbiol 27, 131-142.

Pitkin, J. W., Panaccione, D. G. \& Walton, J. D. (1996). A putative cyclic peptide efflux pump encoded by the TOXA gene of the plant-pathogenic fungus Cochliobolus carbonum. Microbiology 142, 1557-1565.

Ransom, R. F. \& Walton, J. D. (1997). Purification and characterization of extracellular $\beta$-xylosidase and $\alpha$-arabinosidase from the plant pathogenic fungus Cochliobolus carbonum. Carbohydr Res 297, 357-364.

Rubartelli, A., Cozzolino, F., Talio, M. \& Sitia, R. (1990). A novel secretory pathway for interleukin- $1 \mathrm{~b}$, a protein lacking a signal sequence. EMBO J 9, 1503-1510.

Scott-Craig, J. S., Panaccione, D. G., Cervone, F. \& Walton, J. D. (1990). Endopolygalacturonase is not required for pathogenicity of Cochliobolus carbonum on maize. Plant Cell 2, 1191-1200.

Scott-Craig, J. S., Cheng, Y.-Q., Cervone, F., De Lorenzo, G., Pitkin, J. W. \& Walton, J. D. (1998). Targeted mutants of Cochliobolus carbonum lacking the two major extracellular polygalacturonases. Appl Environ Microbiol 64, 1497-1503.

Siever, D. A. \& Erickson, H. P. (1997). Extracellular annexin II. Int $J$ Biochem Cell Biol 29, 1219-1223.

Southerton, S. G., Osbourn, A. E., Dow, J. M. \& Daniels, M. J. (1993). Two xylanases from Gaeumannomyces graminis with identical N-terminal amino acid sequences. Physiol Mol Plant Pathol 42, 97-107.

Sposato, P., Ahn, J.-H. \& Walton, J. D. (1995). Characterization and disruption of a gene in the maize pathogen Cochliobolus carbonum encoding a cellulase lacking a cellulose binding domain and hinge region. Mol Plant-Microbe Interact 8, 602-609.

Van Hoof, A., Leykam, J., Schaeffer, H. J. \& Walton, J. D. (1991). A single $\beta 1,3$-glucanase secreted by the maize pathogen Cochliobolus carbonum acts by an exolytic mechanism. Physiol Mol Plant Pathol 39, 259-267.

Vroemen, S., Heldens, J., Boyd, C., Henrissat, B. \& Keen, N. T. (1995). Cloning and characterization of the bgxa gene from Erwinia chrysanthemi D1 which encodes a $\beta$-glucosidase/ xylosidase enzyme. Mol Gen Genet 246, 465-477.

Whitehead, T. R. (1995). Nucleotide sequences of xylan-inducible xylanase and xylosidase/arabinosidase genes from Bacteroides ovatus V975. Biochim Biophys Acta 1244, 239-241. 
Whitehead, T. R. \& Hespell, R. B. (1990). The genes for three xylan-degrading activities from Bacteroides ovatus are clustered in a 3.8-kilobase region. J Bacteriol 172, 2408-2412.

Wong, K. K. Y., Tan, L. U. L. \& Saddler, J. N. (1988). Multiplicity of $\beta$-1,4-xylanases in microorganisms. Microbiol Rev 53, 305-317.

Wu, S.-C., Kaufmann, S., Darvill, A. G. \& Albersheim, P. (1995).

Purification, cloning, and characterization of two xylanases from Magnaporthe grisea, the rice blast fungus. Mol Plant-Microbe Interact 8, 506-514.

Wu, S.-C., Ham, K.-S., Darvill, A. G. \& Albersheim, P. (1997).
Deletion of two endo- $\beta$-1,4-xylanase genes reveals additional isozymes secreted by the rice blast fungus. Mol Plant-Microbe Interact 10, 700-708.

Ye, R. D., Wun, T.-C. \& Sadler, J. E. (1988). Mammalian protein secretion without signal peptide removal. J Biol Chem 262, 4869-4875.

Received 7 October 1998; revised 31 December 1998; accepted 25 January 1999. 